DE DE GRUYTER OPEN
Journal of Intercultural Management

Vol. 6, No. 3, September 2014, pp. 143-150

DOI 10.2478/joim-2014-0025

Marcela Contreras Rebecca Loera*

Universidad de Occidente

\title{
The formulation of the strategy in the cooperative
}

\begin{abstract}
The strategy is an important process for change in organizations; is an effort to find an ever closer relationship between society, individuals and their organizations, in an essentially interrelated world. The organization not only has a context but also an internal configuration and the cooperative is not an exempt of this. This document presents partial findings of the study which analyzed the formation of the fishing cooperative strategy in Sinaloa and the factors involved for its creation. Data were collected through semistructured interviews to fishermen whose play the roles of managers in cooperatives. The results indicate that in the fishing cooperative, its strategy arises from the mind of a manager with limited cognitive abilities and limited information, biased and considering the manager's intuition, and because the members of the cooperative said that the fishing process is well-know to him but he is not qualified to lead to the organization. From the above it is concluded that in the fishing cooperative, its strategies are formed informally, in the short term, from its management capabilities, identifying the need for training programs for members of the organization, so that they will have the elements necessary to formulate and implement appropriate strategies for these organizations.
\end{abstract}

Key words: Formulation of strategies, fishing cooperative

\section{Introduction}

The current organization seeks to adapt to the environment by implementing various mechanisms, but the change seems to be a challenge that is difficult due to the turbulent environment in which they operate.

Beginning from the idea that there is a complex reality on which we have to act together, with a shared directionality and with the intention of transforming, strategic thinking can be an important factor in achieving this perspective.

The strategy is an important process for change in organizations; it is an effort to find an ever closer relationship between society, individuals and their organiza-

*marcelac25@hotmail.com 
tions, in an essentially interrelated world. The organization not only has a context but also an internal configuration, it is not only planed but also implemented, "the strategy ventured into building the future" (Matus:1995).

The changes in the labor world cause organizations in order to survive they must pay attention to their environment since it is analyzed give certain expressions that show complex situations where elements are mixed economic, social, legal, moral, ethical.

In the case of the Mexican organizations, their study has social and economic implications regarding a scenario that shows a country with diverse organizational realities. Rodriguez (2006) notes that organizations in Sinaloa have seen the need to initiate a process of implementing strategies to achieve the desired goals and meet the challenges of globalization. The objective of this paper is to analyze how the strategy is formed in the fishing cooperative from Sinaloa that seeks to survive and to remain in the market and the factors involved for its creation.

\section{Methodological references}

Qualitative methodology refers in the broadest sense to research that produces descriptive data which address this research under this paradigm, because this method has as its central idea how people, groups and organizations hold different tasks, rather than why they made them. This research examined the ways in which people apply processes and common sense to perceptions of specific situations in order to interpret the reality of the Sinaloa cooperative that has managed to remain. For data collection semi-structured interview was used to twelve fishing cooperative's CEO's, additionally it was analyzed internal documents such as minutes of meetings and reports with results of the cooperative.

\section{Theoretical references}

The strategy is a significant instrument for changing business; its formation is given differently, depending on the size of the organization. Over time, the authors define strategy from different perspectives, Chandler (1962) indicate it as the element that determines goals and objectives of a long term, while for Andrews (1969) represents a pattern of objectives, purposes or goals and major policies to achieve these goals. Ansoff (1965) gives a definition profiled into action considering that the strategy is a wire with four components (scope of the product/market; growth vector; competitive advantage and synergy) that runs between the activities of the company and the products/markets, making it a rule to make decisions.

For Mintzberg (1997) the term strategy is the pattern of a series of actions that occur over time. He emphasizes the action, as the company would have a strategy even if they don't make plans, although no one take the time to establish formal goals. The study of the strategy has spread and operated from different analysis and 
approaches so that the objective of this study is to know the different ways that had been created in the fishing cooperative.

For purposes of appeal to a theory that helps explain the phenomenon being studied, it has been addressed the proposal of Henry Mintzberg, who develops a historical approach to define the strategy. To this author the objectives, plans and resources of the company, at any given time, are not more important than everything the company has done and actually is doing. In his opinion, the standard model attaches importance to the analysis while his approach emphasizes the action, arguing that the company would have a strategy even if they did not have plans, even though no one in the company take time to establish formal goals. Mintzberg (1999) notes that there is no optimal way to formulate strategies, nor a better form of organization, and clarifies that all forms work well in different contexts. The classification corresponds to schools of thought associated with a particular model of strategy formation, organized into three groups: a)prescriptive (design, planning and positioning), b)descriptive (enterprise, cognitive, learning, political, cultural and environmental) and c)inclusive (settings).

\section{Features of prescriptive and descriptive schools}

The design school; its model is based on assessing external and internal aspects; pretends the organization to anticipate the future, representing the constantly changing environment; this school has the manager as its centerpiece. The formulation of the strategy is a conceptual process of thought.

In the school of planning, strategy formulation is a process, controlled, conscious and formal that the organization performs, divided into steps, each delineated by a list of aspects to consider. Strategies emerge from a fully developed process and then are implanted, which is why planning should be done with care.

The school of positioning; strategy formulation is based on an analytical process, differing by placing limits on the strategies on given situations, basing strategy formation in the market positioning of the organization. It also indicates that the economic situation in the market should be defined at this time or in the future.

In business school, strategy implicitly exists in the mind of the leader which is regarded as an integrated perspective, with a sense of direction in the long term, as a vision of the future of the organization. The process of strategy formation is semiconscious and is rooted in the experience and intuition of a visionary leader. This leader maintains close personal control both in the formulation of the vision and its subsequent implementation process, little can be said about its main features because it is considered as a black box enclosed in the human brain.

The cognitive school poses as main premises of the training model the following: a) The formation of strategies is a cognitive process that takes place in the mind of the strategist, b) In consequence, strategies are prospects, or concepts, which are 
formed in that mind; c) The environment of the strategist is a complex environment, their limited cognitive capacities, and consequently, receiving information is restricted and biased and strategy formation process thereby distorts; and d) As a result of individual cognitive differences, strategists vary significantly in their formation styles of strategies.

Learning school; its main features can be summarized in the following points: a) The development of strategies in the form of a learning process over time in which the formulation and implementation are indistinguishable phases; b) Although the process can be focused on a leader, as will usually be the collective system which is subject to the learning process. This recognizes the existence of many potential strategists in most organizations; c) Learning develops an emerging form through strategic initiatives taken in different parts of the organization and in response to external pressures and events. These strategies appear first as patterns derived from the past and only later perhaps as deliberate plans for the future, and finally as perspectives to guide the general conduct; and d) The leader's role is not to develop deliberate strategies, but to lead the process strategic learning through which new strategies can emerge. Therefore, management must combine the subtle relationships between thought and action, control and learning, stability and change.

Power school; its main assumptions are summarized in the following points: a) The training process is fundamentally political strategies and may have its heart in the organization (micro) or outside (macro); b) In the micro-political processes there is no dominant player, but rather a set of groups or coalitions that compete for control of the organization; and c) Macro- processes, the organization promotes its own welfare through the development of deliberate aggressive strategies political nature.

In the culture school; the formulation of ideas becomes the direction of the sense of community, with its main premises as the following: a) The formulation of the strategy is fundamentally a process of collective behavior based on the beliefs shared by members of the organization; b) As a result, the strategy adopts mainly as a way of perspective, position or tactics, is not necessarily based on explicit actions and its intentions are reflected in models that make it deliberate; $c$ ) The way of organizing and controlling systems are widely normative, based on shared beliefs influence; d) Given the importance of internal belief system, the organization tends to be offensive in relation to an environment that appears to be passive and diffuse its influence; and e) Culture and especially ideology, do not encourage strategic change but rather promotes the maintenance of the existing strategy .

Environment school; the premises of this is derived from two theories flows developed in the field of organization theory: the contingent approach and the theory of population ecology postulates that external conditions force the organization to strategies. These assumptions are summarized in the following points: a) The 
environment in general expressed by a set of abstract forces, determines the strategy because it forces the organization or its attributes of ecological niches, those who oppose this adaptation eventually die; b) There is no real internal strategist or internal process of strategy formulation. Leadership is a myth and the organization adopts a completely passive role in this process; and c) The strategies are positions where organizations niches remain until exhausting what nourishes.

Settings School; Mintzberg (1990) states that the premises of this school are the premises of all the above, combined in well-defined contexts, and states as follows: a) The behavior of organizations are best described in terms of configuration - different groups and integrated are dimension related with state and time-; b) In particular, the formation of strategies is an episodic process in which a particular organization, adapted to a particular environment type, makes the process of concrete form for a period of time differentiated; and c) Accordingly, the design process can be conceptual or formal planning, systematic analysis or vision intuitive knowledge can be individual or collective or political learning, which can be guided by a personalized leadership for organizational culture or the environment, and the resulting strategies can take the form of plans or models, tactics, positions or perspectives, but everything must be in your own time and in their own context.

\section{Research results}

In Mexico, the fishing cooperatives operate in rural communities, built by its inhabitants, representing an alternative to the creation of jobs, development of fisheries in an organized likewise play an important role in social and economic development.

Based on the proposal of Mintzberg and the field work results can be pointed out what the fishing cooperative have made regarding their strategy formation process that has allowed them to survive and stay for more than seventy years. This was made from what Minzberg (1997) indicate, whom says that organizations historically reflect various characteristics of strategies training schools because it believes that the strategy is the pattern of a series of actions that occur over time.

The interviewees are from twelve fishermen who play the role of fishing cooperative's CEO's, elected by the mayority of the cooperative's partners, who last as $\mathrm{CEO}$ for 2 years and whose ages range between 30 and 45 years old. They live in the communities where the cooperative is located, most of them have primary and secondary studies, are married and their fishing seniority is more than 25 years. (See Table 1) 
Table 1. Characteristics of fishermen - Directors of the cooperative

\begin{tabular}{|l|l|}
\hline Characteristic & Fishermen - CEO \\
\hline Between 30 and 45 years old & $92 \%$ \\
\hline Marital status Married & $100 \%$ \\
\hline Studies of primary and secondary & $70 \%$ \\
\hline Average age in fisheries & More than 25 years \\
\hline They live in the community where the cooperative is located & $100 \%$ \\
\hline
\end{tabular}

Source: Author, with data from interviewed

In relation to the formation of the cooperative strategy, interviewees agree that they know very well the art of catching species, mainly for shrimp and scale, however they recognize that when they integrate as directors of the organization they are not prepared for the development of leadership roles because they do not know the job's responsibilities and learn to run the cooperative as time passes, from the experiences and recommendations of the counter or the chairman of the Federation of cooperatives in which are embedded.

This tells us that in the fishing cooperatives the strategy formation as the cognitive school is because it is a product of the ideas of its directors, arising from his mind, limited by their cognitive abilities causing that strategies and their implementation is distorted .

On the other hand, managers indicate that the strategies implemented in the cooperative, are the result of the decisions of the members of the cooperative and the regulatory framework of these organizations indicates that each partner has a vote. Therefore, in assembly meetings decisions are made from what most voted on. Thereby cooperatives are identified in the power school is because there are micropolitical processes in which there is no dominant player but the members and dominant groups engage to define the actions that are going to be implemented. The formation of the fishing cooperative strategy manifests considering the profiles of their members and their ways of thinking, but there are also external factors that influence the decisions that managers and unions say that they operate with many needs, such as economical and financial necessities, because the shrimp catch (species with the highest market value) is carried out for six months a year, so the rest of the year, the government sets ban to ensure the reproduction of the species forcing them to perform various low-paid activities that generates cash shortage, debt and the need for funding sources to high costs.

On the other hand, Federal government provides various supports to cooperatives in order to implement changes focused in the care of the environment; among the supports are changing for ecological engines and fuel support. Fishermen recognize that it is important to comply with these accusations and even attend the calls for support, they do not always benefit from them. This shows that in the for- 
mation of the fishing cooperative strategies, school is present in the environment and external conditions exist that force the organization by certain strategy

\section{Conclusions}

Some countries base their fisheries development policy in establishing fishing cooperatives and found to be successful for some but not for others. In Mexico, these cooperatives are located in rural areas whose economy is based on the exploitation of natural resources represent an option for economic and social development of their communities.

International organizations such as FAO (2009) point out that even if the fishing cooperatives, throughout its history, can have negative connotations, there is recognition that could increase the stability and resilience of fishing communities.

In relation to the formation of a strategy, it differs from one organization to another, since the characteristics of each, are pivotal to their behavior. Knowing how they operate and relate the strategies regarding leadership roles and organizational processes allow us to have an approach to the reality of the life in local organizations.

This research shows that in the fishing cooperative, the strategy is formed internally considering the profile of the fisherman playing the role of manager and his acting because of the low level of their education and the inexistent training to direct an organization, make them realize the strategies that in their opinions are required by the organization, but on the other hand, it is recognized that the involvement of powerful groups of members of the cooperative and external elements such as governmental rules for the development of fishing activity, also influence into the strategy formation for the cooperative; identifying that there isn't an optimal path to follow in order to create strategies due to the diversity of the particular contexts each cooperative face .

Being aware of the know-how and the processes that are followed to deploy strategies, allow their managers to have clear recognition that the strengths of a company are its resources for growth and transformation, regarding the work of the organization, considering the past, the present and the future.

From the above, it is recommended that fishermen who have management positions receive training on internal and external elements to improve the process of developing cooperative strategies, focused on organizational change and improving conditions for its members.

\section{References}

Andrews, Kenneth R. (1969). The concept of corporate strategy. Dow Jones-Irwin, Richard D. Irwin Inc, Homewood IL.

Ansoff, H. Igor (1965). Corporate strategy: an analytic approach to business policy for growth and 
expansion. Nueva York. Mc Graw Hill.

Chandler, Alfred (1962), Strategy and structure: chapters in the history of the american industrial enterprise, MIT Press, Cambridge, Massachussets.

Matus, Carlos (1995), Chimpancé, Machiavello y Ghandi. Estrategias Políticas, Fondo Editorial Altadir, 1․ Edición, Venezuela

Mintzberg, Henry (1990). Strategy formation: Schools of thought. En perspectives on Strategy Management. Ed. James W. Frederickson. Nueva York:Harper Business.

Mintzberg, Henry, James Brian Quinn y John Voyer (1997) El Proceso Estratégico, Prentice Hall hispanoamericana, $2^{a}$ edición, México

Mintzberg, Henry, Bruce Ablstrand y Joseph Lampel (1999) Safari a la estrategia.

Organización de las Naciones Unidas para la Alimentación y la Agricultura (FAO,2009). Las cooperativas en la pesca en pequeña escala: favorecer el éxito mediante el empoderamiento de la comunidad. Año internacional de las cooperativas. Issue Brief Series. http:// www.fao.org/docrep/016/ap408s/ap408s.pdf

Consultado el 10 de agosto de 2013.

Rodríguez, Peñuelas Marco Antonio (2006). Estrategias de desarrollo de la empresa sinaloense. Editada por UAS, Promep. México.

Shumpeter, Joseph A. (1976). Teoría del desarrollo económico. FCE. México. 